\title{
Trial Test of Fish Attractor "Piknet" Device in Saltwater Fish Tank
}

\author{
Nurul Rosana ${ }^{1,}$, , Suryadhi ${ }^{2}$, Safriudin Rifandi $^{2}$ \\ ${ }^{1}$ Department of Fisheries, Faculty of Engineering and Marine Science, Hang Tuah University, \\ Indonesia \\ ${ }^{2}$ Department of Electrical Engineering, Faculty of Engineering and Marine Science, Hang Tuah \\ University, Indonesia
}

\begin{abstract}
The fish attractor called "Piknet" is an instrument designed based on sound wave to maximize the fishing activity by gill-netters. The sound wave are used in "Piknet" ranged from 100-1000 Hz. The "Piknet" test was conducted to know the range of sound wave which has well responses by salt water fish. The result showed that the sound wave ranged $500-1000 \mathrm{~Hz}$ is the best one.
\end{abstract}

\section{Introduction}

As Bregman points out, the world abounds with sound and animals use sound to glean a great deal of information about their environment [1]. Especially in sea, fish use sound to do so many activites supported their live : prelude or during mating, in warning of danger, and maybe in many other context that we have yet to understand. This fact, let human to improve a lot of technologies which can increase the fishing productivity in sea.

Fish's response to sounds are in very wide range of infrasonic, sonic, or ultrasonic [2]. One of the fishing technology developed by human is fish attractor. In Indonesia, this technology is starting to be studied and developed by both government and private parties. Some types of proven are pikat, alpine and electrofish [3]. In international issue, people are concern to the effects of human-generated sound on fish and other aquatic organisms by the influence of human-generated voices on fish and other aquatic organisms [4].

The fish attractor called "Piknet" is an instrument designed by wave sound based. This technology is intended to help gill-netters to increase their number of fish catching. Traditional fisherman in Indonesia are less of technological minded in their daily fishing. This lead in decreasing their income as less of fish that they can obtain daily. In the other hand, modern fisherman which have big of capitals do a huge fishing in many Indonesian areas [5].

Piknet can be one of solution to the problem and hopefully this device can be more developed in the near future. The sound wave used in "Piknet" ranged from $100-1000 \mathrm{~Hz}$ [3]. This paper will describe the experimental which was conducted to find the best responsive range of Piknet frequency for salt water fish.

\footnotetext{
* Corresponding author: nurul.rosana@hangtuah.ac.id
} 


\section{Research Method}

Two range of frequency will be examined to 18 fish in salt water. The frequency ranged between $100-500 \mathrm{~Hz}$ and $500-1000 \mathrm{~Hz}$. The selection of these frequency range is based on related literatures. The test was conducted 3 times in 15 minutes for each frequency range to observe the fish responses. Piknet device is immersed and installed on the right side of saltwater tank (Fig. 3).

Figure 1 show the device called Piknet. The cross-sectional dimension is $9 \mathrm{~cm} \times 6 \mathrm{~cm}$ with 4.5 watts and 9 volt battery in power consumption. Figure 2 shows the step by step procedure of experiment.

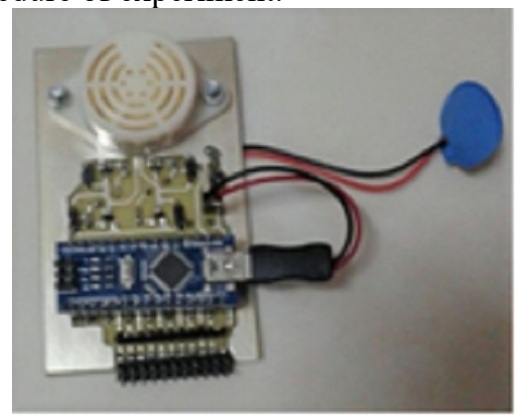

Fig 1. The fish caller device "Piknet"

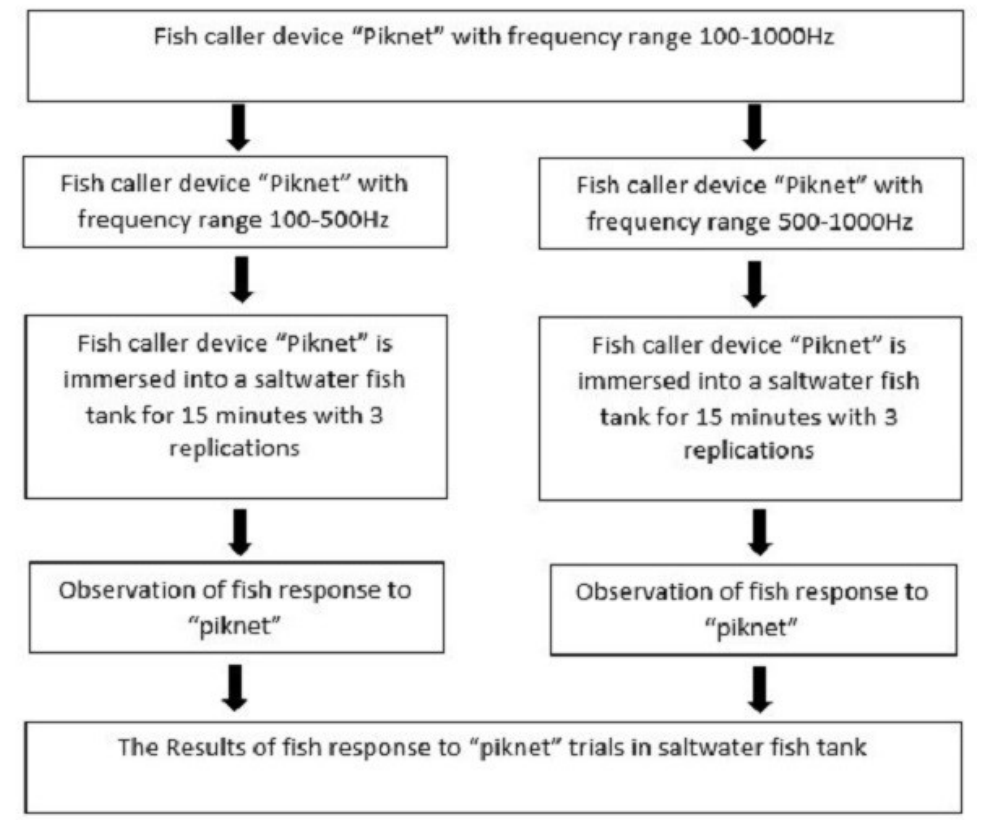

Fig 2. The experimental diagram

\section{Result and Discussion}

Experiment was conducted as the diagram showed in Figure 2. For frequency ranged $100-$ $500 \mathrm{~Hz}$, the fish do not have a significant response to come to Piknet after 10 minutes. Figure 3 shows that phenomena, that all of fish are in the left side or opposite of Piknet. 
Otherwise, Piknet which have frequency range between $500-1000 \mathrm{~Hz}$ are very attractive for various types of fish after 2 minutes experiment (See Figure 4).

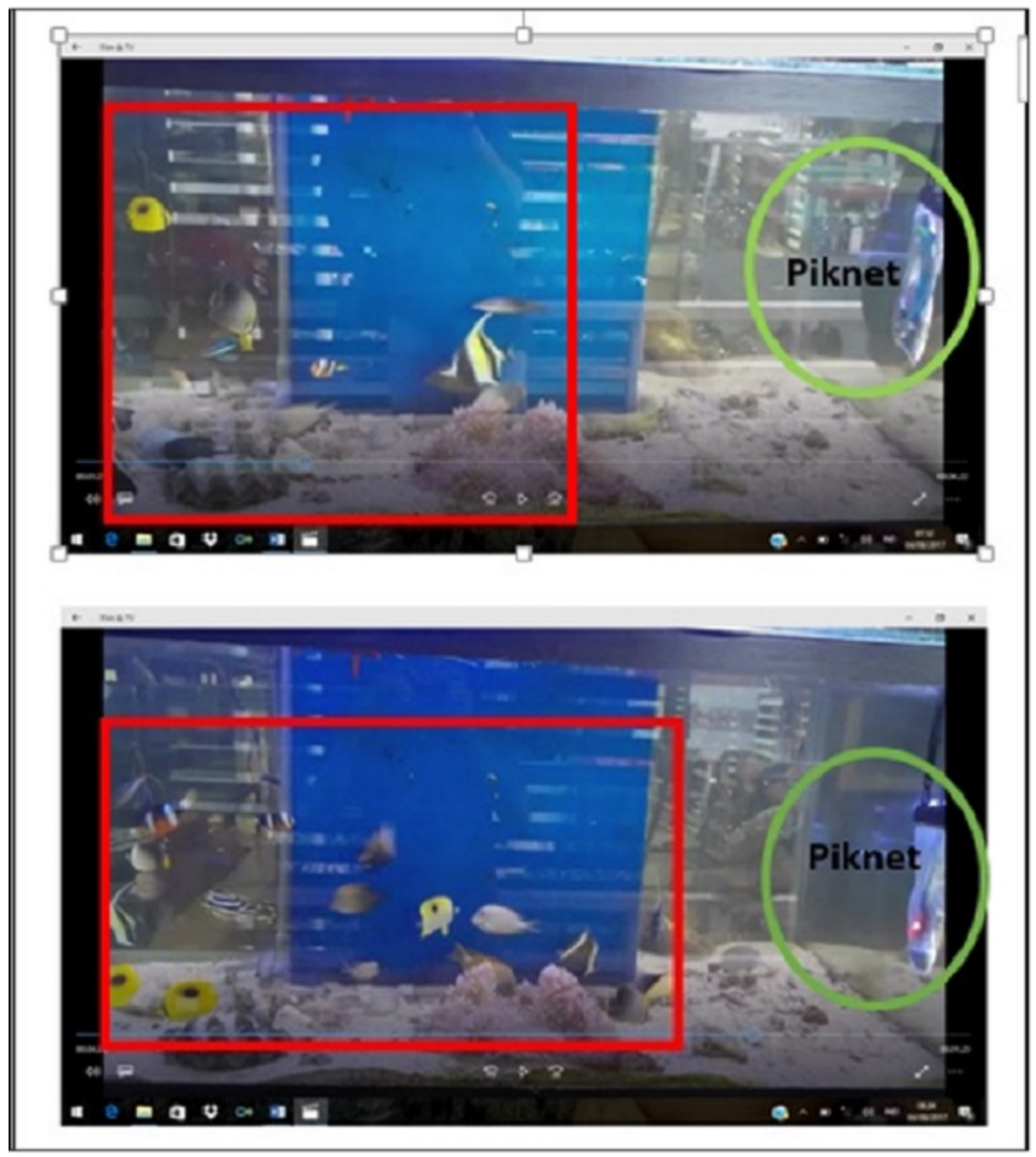

Fig 3. The movement of fish after 10 minutes "Piknet" at the frequency of $100-500 \mathrm{~Hz}$

Informations was brought by sound signals explains the state of threatening dangers, aggressive circumstances to frighten the enemy, or the call of favor [6]. Sound is also produced from other behavioral impacts such as eating, moving, avoiding enemies, and reproduction (sexuality and enlargement phases) [7]. From Table 1, it can be seen that the most responsive frequency is $500-1000 \mathrm{~Hz}$. This frequency can attract $88 \%$ of fish in salt water tank, other wise only $22 \%$ of fish. 

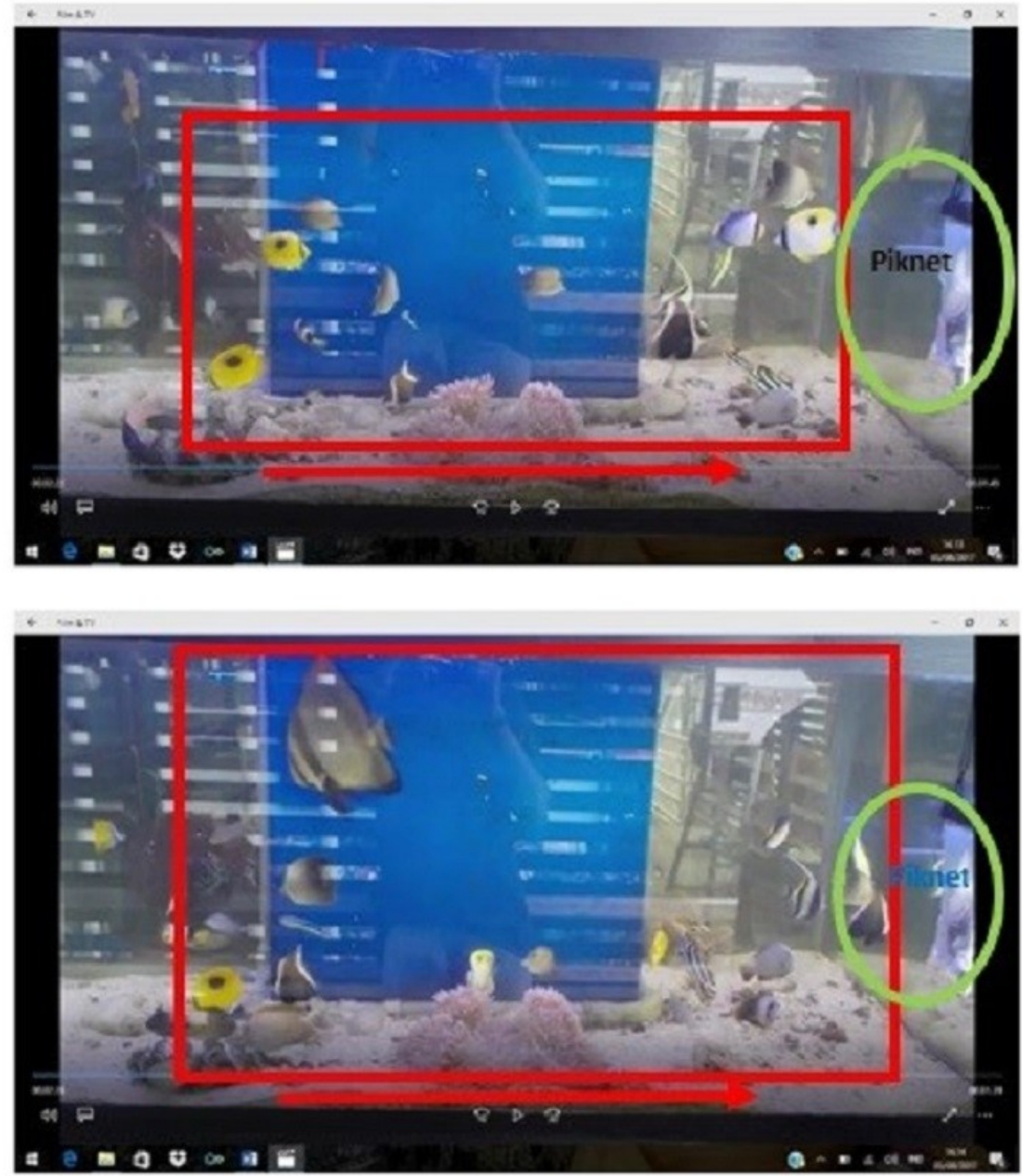

Fig 4. The movement of fish after 2 minutes "Piknet" at the frequency of 500-1000Hz

Tabel 1. Quantity and response of fish to "piknet"

\begin{tabular}{|c|c|c|c|c|}
\hline $\begin{array}{c}\text { Range of } \\
\text { Frequency } \\
\text { (Hz) }\end{array}$ & $\begin{array}{c}\text { Quantity of } \\
\text { Fishes in } \\
\text { Saltwater } \\
\text { Fish Tank }\end{array}$ & $\begin{array}{c}\text { Quantaty of } \\
\text { Fish } \\
\text { Response }\end{array}$ & $\begin{array}{c}\text { Percentage } \\
\mathbf{( \% )}\end{array}$ & Fish response \\
\hline $100-500$ & 18 & 4 & 22 & $\begin{array}{c}\text { Most of the amount of fish in the } \\
\text { left side of the tank, opposite of } \\
\text { Piknet. }\end{array}$ \\
\hline $500-1000$ & 18 & 16 & 88 & $\begin{array}{c}\text { Most of the amount of fish begin to } \\
\text { come to the "Piknet" that installed } \\
\text { on the right of the tank, and rotate } \\
\text { back to the other side then return } \\
\text { closer "Piknet" }\end{array}$ \\
\hline
\end{tabular}




\section{Conclusion}

The experiment show that "Piknet" can work very well in the frequency ranged between $500-1000 \mathrm{~Hz}$. This result is one of the step stone for further development toward establishing national fish attractor called "Piknet".

\section{References}

1. Bregman AS, Auditory Scene Analysis: the Per-ceptual Organization of Sound, MIT Press, Cambridge, MA, (1990)

2. G.V. Nikolsky, The Ecology Of Fishes. Translet From Russian. L Birket. Academic Press. Inc. London, (1963)

3. N. Rosana and Suryadhi, Determination of Sound Waves for Design of "Piknet". Proceding of Hang Tuah University National Marine Seminars, Surabaya, (2017)

4. A.N. Popper and M.C. Hastings, The Effects of Human-Generated Sound on Fish, Integrative Zoology, 4, 1, pp. 43-52 (2009)

5. Hikmah, Mutiara, Jurnal H Int., 11, (2013)

6. Pratt, Mary M, Better Angling With Simple Science: The White Friars Press. London, (1975)

7. A.N. Popper and C.Plat, Inner Ear and Lateral Line P. 116 - 117. In David H. Evans. (ed). The Physiology Of Fishes. CRC Press. Boca Raton, (1993) 